\title{
Konsumsi makanan kariogenik dan kebiasaan menggosok gigi dengan kejadian karies gigi pada anak
}

\author{
Riska Wandini ${ }^{1}$, Yuniati $^{*}$
}

1Dosen Program Studi Ilmu Keperawatan Universitas Malahayati. Email: onienay@yahoo.co.id ${ }^{2}$ Perawat di RS Pertamina Bintang Amin Bandar Lampung. *Email: yuniaticantik18@gmail.com

\begin{abstract}
Caries prevalence and risk factors among children aged 4 to 6 years old in Bandar Lampung-Indonesia
\end{abstract}

Background: Dental caries are still a matter of oral health in large industrialized countries , which affects $60-90 \%$ of the school children and most adults.Dental caries can be experienced by everyone and can arise on one or more dental surfaces.For example, from email to dentin or to Pulpa. Caries are due to various reasons, including are carbohydrates, microorganisms and saliva, tooth shape surfaces. Based on data by interviewed at the time were conducted on 20 Students at kindergarten Kuntum Mekar and Setia Bandar Lampung obtained of 14 (70\%) They have a cariogenic food intake during the day and had the poorest teeth brushing habits, characterized by dental caries of $7(30 \%)$.

Purpose: Knowing caries prevalence and risk factors among children aged 4 to 6 years old in Bandar LampungIndonesia

Methods: A quantitative research type (analytic), with cross sectional approach and population was all children at Kuntum Mekar and Setia kindergarten in Bandar Lampung. By formula Slovin got sample number of 80 students. Data analysis Used the chi-square statistical test.

Result: Finding the frequency of consumption of high cariogenic foods As many as of 72 respondents $(86 \%)$, had a poorest tooth brushing habits, of 60 respondents $(75 \%)$, and had a dental caries as many as of 63 respondents $(83.8 \%)$, with the p-value $=0.022$ and 0.002 ; OR: 5,357 and OR: 7,333 .

Conclusion: There is a correlation the factors cariogenic food intake during the day and had the poorest tooth brushing habits with dental caries occurance.

Suggestions: To be pay attention for parent and teachers to remember that children reduce the consumption of cariogenic food and improving in brushing teeth habit

Keywords: Cariogenic food intake; Brushing teeth habit; Dental caries.

Pendahuluan: Karies gigi masih menjadi masalah kesehatan mulut di negara-negara industri besar, yang mempengaruhi $60-90 \%$ dari anak-anak sekolah dan sebagian besar orang dewasa. Karies gigi dapat dialami oleh semua orang dan dapat timbul di satu permukaan gigi atau lebih. Misalnya dari email ke dentin ataupun ke pulpa. Karies dikarenakan berbagai sebab, diantaranya adalah karbohidrat, mikroorganisme dan air ludah, permukaan bentuk gigi.Berdasarkan hasil prasurvei yang dilakukan pada siswa yang juga diwawancarai pada saat itu dilakukan pada 20 siswa di TK Kuntum Mekar dan TK Setia Bandar Lampung didapatkan data 14 siswa (70\%) diantaranya mengkonsumsi makanan kariogenik dan memiliki kebiasaan menggosok gigi yang kurang baik ditandai dengan karies gigi dan 7 siswa (30\%) diantaranya mengatakan jarang mengkonsumsi makanan kariogenik dan memiliki kebiasaan menggosok gigi cukup baik atau minimal dua kali sehari saat pagi sesudah makan dan malam sebelum tidur.

Tujuan: Diketahui hubungan antara konsumsi makanan kariogenik dan kebiasaan menggosok gigi umur 4-6 tahun dengan kejadian karies gigi pada anak-anak di Bandar Lampung Indonesia.

Metode: Penelitian kuantitatif (analitik), dengan pendekatan cross sectional. Populasi dalam penelitian ini adalah anak-anak TK Kuntum Mekar dan TK Setia di Bandar Lampung, dengan jumlah sampel 80 murid.Pengambilan sampel menggunakan rumus Slovin.Analisis data menggunakan uji statistik chi-square.

Hasil: Menunjukkan distribusi frekuensi konsumsi makanan kariogenik yang sering sebanyak 72 responden (86\%), kebiasaan menggosok gigi yang buruk sebanyak 60 responden $(75 \%)$. Karies gigi pada anak-anak dengan karies sebanyak 63 responden (83,8\%). Ada hubungan antara konsumsi makanan kariogenik dengan kejadian karies gigi pada anak dengan nilai $p$-value $=0,022(p$-value<0,05), serta diperoleh nilai OR : 5.357. Ada 
Konsumsi makanan kariogenik dan kebiasaan menggosok gigi dengan kejadian karies gigi pada anak

hubungan anatara menggosok gigi dengan kejadian karies gigi pada anak dengan nilai $p$-value $=0,002$ ( $p$ value<0,05), serta diperoleh nilai OR : 7.333 .

Simpulan: Ada hubungan antara konsumsi makanan kariogenik dan kebiasaan menggosok gigi dengan kejadian karies gigi pada anak TK Kuntum Mekar dan TK Setia di Bandar Lampung Tahun 2019. Saran dalam penelitian ini diharapkan anak-anak mengurangi konsumsi makanan kariogenik dan mengetahui kebiasaan menggosok gigi yang benar.

\section{Kata Kunci: Konsumsi makanan kariogenik; Kebiasaan menggosok gigi; Karies gigi}

\section{PENDAHULUAN}

Karies gigi masih menjadi masalah kesehatan mulut di negara-negara industri besar, yang mempengaruhi $60-90 \%$ dari anak-anak sekolah dan sebagian besar orang dewasa.Sejak dini anak perlu didik untuk dapat memelihara kesehatan gigi dan mulut. Karies pada anak-anak yang tidak dirawat juga dapat mengakibatkan hal-hal yang tidak menguntungkan, seperti rasa sakit, infeksi, gangguan aktifitas sehari-hari, gangguan pertumbuhan dan penurunan kualitas hidup (Hidayat, \& Tandiari, 2016).

Di Indonesia telah terjadi perubahan pola makan akibat dari meningkatnya penggunaan refined carbohydrat atau dalam kehidupan seharihari dikenal sebagai kembang gula, coklat dan penggunaan lain yang banyak mengandung sukrosa. Makanan tersebut umumnya mudah melekat pada permukaan gigi. Bila anak malas untuk membersihkan giginya, maka sisa makanan tersebut diubah menjadi asam oleh bakteri yang terdapat didalam mulut, kemudian dapat menyebabkan terjadinya karies gigi.masyarakat Indonesia di Provinsi Lampung yang mempunnyai masalah gigi dan mulut adalah sebesar $57,6 \%$ dan sekitar 10,2\% mendapat pelayanan tenaga medis (Kementrian Kesehatan Republik Indonesia, 2013).

Dengan menggosok gigi, kebersihan gigi dan mulut pun akan terjaga, selain itu dapat menghindari terbentuknya lubang-lubang gigi, penyakit gigi dan gusi (Hongini, \& Aditiawarman, 2012).

Penyakit karies dapat dicegah dengan cara rajin dan waktu yang tepat dalam menggosok gigi (Erwana, 2013); Pintauli, Bachtiar., \& Rahardjo, 2019).

Berdasarkan hasil prasurvei yang dilakukan pada siswa yang juga diwawancarai pada saat itu dilakukan pada 20 siswa di TK Kuntum Mekar dan TK Setia Bandar Lampung didapatkan data 14 siswa (70\%) diantaranya mengkonsumsi makanan kariogenik dan memiliki kebiasaan menggosok gigi yang kurang baik ditandai dengan karies gigi dan 7 siswa $(30 \%)$ diantaranya mengatakan jarang mengkonsumsi makanan kariogenik dan memiliki kebiasaan menggosok gigi cukup baik atau minimal dua kali sehari saat pagi sesudah makan dan malam sebelum tidur.Erupsi gigi primer yang pertama dimulai pada umur 6 bulan sampai 2 tahun, kemudian secara bertahap akan tanggal dimulai pada umur 6 tahun (Mansjoer, Suprohaita, \& Setiowulan, 2008).

Karies gigi merupakan salah satu penyakit jaringan keras gigi, yaitu email dan sementum yang disebabakan oleh aktivitas suatu jasad renik dalam suatu karbohidrat yang dapat diragikan.Tandanya adalah demineralisasi jaringan keras gigi yang kemudian diikuti oleh kerusakan bahan organiknya.Akibatnya terjadi invasi bakteri dan kematian pulpa serta penyebaran infeksinya kejaringan periapeks yang dapat menyebabkan nyeri (Hidayat, \& Tandiari, 2016). Caries atau Karies dalam bahasa Indonesia, sebenarnya bukan istilah untuk lubang gigi.Dalam situs dokter gigi dijelaskan bahwa karies adalah istilah untuk penyakit infeksi.Karies yang terjadi pada gigi disebut karies gigi (Mumpuni, \& Pratiwi, 2013). Karies gigi dapat dialami oleh semua orang dan dapat timbul pada satu permukaan gigi atau lebih, misalnya dari email kedentin atau kepulpa.Karies dikarenakan berbagai sebab, diantaranya adalah karbohidrat, mikroorganisme dan air ludah, permukaan bentuk gigi. Karbohidrat yang tertinggal didalam mulut dan mikroorganisme, merupakan penyebab dari karies gigi, sementara penyebab terjadinya karies gigi yang tidak langsung adalah permukaan dan bentuk dari gigi tersebut. Gigi dan fisur yang dalam mengakibatkan sisa-sisa makanan mudah melekat dan bertahan, sehingga produksi asam oleh bakteri akan berlangsung dengan cepat dan menimbulkan karies gigi. Karies gigi terdapat diseluruh dunia, tanpa memandang umur, bangsa ataupun keadaan ekonomi. Menurut penelitian dinegara-negara Eropa, Amerika dan Asia, termasuk Indonesia, ternyata $80-95 \%$ anak dibawah usia 18 tahun terserang karies gigi. Patut diketahui bahwa karies gigi terutama terdapat pada

Riska Wandini' Dosen Program Studi llmu Keperawatan Universitas Malahayati. Email: onienay@yahoo.co.id Yuniati ${ }^{2^{*}}$ Perawat di RS Pertamina Bintang Amin Bandar Lampung. *Email: yuniaticantik18@gmail.com 
Konsumsi makanan kariogenik dan kebiasaan menggosok gigi dengan kejadian karies gigi pada anak

manusia dan jarang pada hewan.(Tarigan, 2013; Talibo, Mulyadi, \& Bataha, 2016).

Apabila pulpa terinfeksi, maka seluruh jaringan pulpa harus dibuang agar infeksi tidak menyebar (Ramadhan, 2010).

Gigi susu memegang peranan penting dalam dalam pertumbuhan jasmani dan perkembangan mental, ini dapat dilihat dari berbagai fungsinya yaitu : fungsi mengunyah, untuk pertumbuhan tulang rahang, sebagai pemadu dan fungsi bicara (Susanto, \& Grace, 2011).

Melihat fenomena yang terjadi, maka penulis tertarik untuk melakukan penelitian mengenai adakah hubungan antara konsumsi makanan kariogenik dan kebiasaan menggosok gigi dengan kejadian karies gigi pada anak TK Kuntum Mekar dan TK Setia di Bandar LampungTahun 2019.

\section{METODE PENELITIAN}

Jenis penelitian kuantitatif dengan pendekatan cross sectional dengan variable idependen konsumsi makanan kariogenik dan kebiasaan menggosok gigi dan variable dependent kejadian karies gigi. Populasi dalam penelitian ini adalah seluruh anak-anak TK Kuntum Mekar dan TK Setia di Bandar Lampung, dengan menggunakan rumus Slovin, sampel sebanyak 100 anak. Waktu pelaksanaan penelitian di lakukakan pada bulan juli 2019, dengan questioner berjumlah 9 item. Questioner sudah pernah dilakukan dengan hasil uji validitas valid dan realibiltas Analisis sudah reliabel, data menggunakan uji statistik chi-square.

\section{HASIL}

Tabel 1. Distribusi Faktor Yang Menimbulkan Karies Gigi $\mathbf{N}=80$

\begin{tabular}{lcc}
\hline \multicolumn{1}{c}{ Variabel } & $\begin{array}{c}\text { Frekuensi } \\
\text { (f) }\end{array}$ & $\begin{array}{c}\text { Persentase } \\
(\%)\end{array}$ \\
\hline Konsumsi Makanan Kariogenik & & \\
Sering & 72 & 86,0 \\
Jarang & 8 & 14,0 \\
Kebiasaan menggosok gigi & & \\
Buruk & 60 & 75,0 \\
Baik & 20 & 25,6 \\
Kejadian karies gigi & & \\
Ditemukan & 63 & 83,8 \\
Tidak Ditemukan & 17 & 16,2 \\
\hline
\end{tabular}

Jumlah murid dengan tingkat konsumsi makanan kariogenik sering $72(86,0 \%)$ dan $8(14,0 \%)$ Jarang. Kebiasaan menggosok gigi yang buruk sebanyak $60(75,0 \%)$ dan $20(25,0 \%)$ murid dengan kebiasaan menggosok gigi baik. Adanya karies sebesar $63(83,8 \%)$, sedangkan responden yang tidak karies sebanyak 17 $(16,2 \%)$. Dilakukan terhadap dua variabel yang diduga berhubungan atau berpengaruh satu sama lain (Notoatmodjo, 2012). Analisis Bivariat dalam penelitian ini digunakan untuk mengetahui hubungan antara variabel bebas (konsumsi makanan kariogenik dan kebiasaan menggosok gigi) dengan variabel terkait (kejadian karies gigi).Adapun analisis yang digunakan dalam penelitian ini adalah Chi-Square.

Tabel 2. Hubungan Konsumsi Makanan Kariogenik Dengan Kejadian Karies Gigi

\begin{tabular}{|c|c|c|c|c|c|c|c|c|}
\hline \multirow{3}{*}{$\begin{array}{l}\text { Konsumsi } \\
\text { Makanan } \\
\text { Kariogenik }\end{array}$} & \multicolumn{6}{|c|}{ Kejadian Karies Gigi } & \multirow{3}{*}{$\begin{array}{c}p- \\
\text { value }\end{array}$} & \multirow{3}{*}{ OR (Cl 95\%) } \\
\hline & \multicolumn{2}{|c|}{ Karies } & \multicolumn{2}{|c|}{ Tidak Karies } & \multicolumn{2}{|c|}{ Total } & & \\
\hline & $n$ & $\%$ & $n$ & $\%$ & $\mathrm{~N}$ & $\%$ & & \\
\hline Sering & 60 & 84.2 & 12 & 15.8 & 72 & 100 & & $5.357(1.369$ \\
\hline Jarang & 3 & 41.7 & 5 & 58.3 & 8 & 100 & 0,022 & $20.962)$ \\
\hline
\end{tabular}

Riska Wandini' Dosen Program Studi llmu Keperawatan Universitas Malahayati. Email: onienay@yahoo.co.id Yuniati ${ }^{2^{*}}$ Perawat di RS Pertamina Bintang Amin Bandar Lampung. *Email: yuniaticantik18@gmail.com 
Konsumsi makanan kariogenik dan kebiasaan menggosok gigi dengan kejadian karies gigi pada anak

Dari $72(100,0 \%)$ responden dengan konsumsi makanan kariogenik yang sering terdapat $60(84,2 \%)$ responden mengalami karies gigi dan $12(15,8 \%)$ responden tidak mengalami karies gigi. Sedangkan dari 8 $(100,0 \%)$ responden dengan konsumsi makanan kariogenik jarang terdapat $3(58,3 \%)$ responden yang mengalami karies dan $5(41,7 \%)$ responden tidak karies. Hasil uji statistik didapatkan nilai $p$-value $=0,022$ lebih kecil dari nilai alpha $(p<0,05)$ yang berarti ada hubungan yang bermakna antara frekuensi konsumsi makanan kariogenik dengan kejadian karies gigi. Hasil analisis juga diperoleh nilai $O R=5.357$, responden dengan konsumsi makanan kariogenik sering beresiko mengalami karies gigi 5,3 kali lebih besar dibanding dengan responden yang mengkonsumsi makanan kariogenik jarang. Tentang hubungan perilaku mengkonsumsi makanan manis dengan kejadian karies gigi pada siswa kelas IV SDN 1 Gulung Sulah Bandar Lampung 2012. Berdasarkan hasil penelitian didapatkan bahwa ada sebanyak 54 (94,7\%) dari 57 siswa yang mengkonsumsi makanan manis mengalami karies. (Putri, \& Sari, 2012).

Tabel 3. Hubungan Kebiasaan Menggosok Gigi Dengan Kejadian Karies Gigi

\begin{tabular}{|c|c|c|c|c|c|c|c|c|}
\hline \multirow{3}{*}{$\begin{array}{l}\text { Kebiasaan } \\
\text { Menggosok Gigi }\end{array}$} & \multicolumn{6}{|c|}{ Kejadian Karies Gigi } & \multirow[b]{2}{*}{$p$-value } & \multirow[b]{2}{*}{$\begin{array}{l}\text { OR (Cl } \\
95 \%)\end{array}$} \\
\hline & \multicolumn{2}{|c|}{ Karies } & \multicolumn{2}{|c|}{$\begin{array}{l}\text { Tidak } \\
\text { Karies }\end{array}$} & \multicolumn{2}{|c|}{ Total } & & \\
\hline & $\mathrm{n}$ & $\%$ & $\mathrm{n}$ & $\%$ & $\mathrm{~N}$ & $\%$ & & \\
\hline Baik & 12 & 60.0 & 8 & 40.0 & 20 & 100.0 & & 7.333 \\
\hline Buruk & 55 & 91.7 & 5 & 8.3 & 60 & 100.0 & 0.002 & (2.039- \\
\hline Jumlah & 67 & 83.8 & 13 & 16.2 & 80 & 100.0 & & $26.376)$ \\
\hline
\end{tabular}

Diketahui bahwa dari $20(100,0 \%)$ responden yang memiliki kebiasaan menggosok gigi yang baik terdapat 17 $(60,0 \%)$ responden mengalami karies gigi dan $3(40,0 \%)$ responden tidak mengalami karies gigi. Sedangkan dari $60(100,0 \%)$ responden yang memiliki kebiasaan menggosok gigi kurang baik terdapat $46(91,7 \%)$ responden yang mengalami karies dan $14(8,3 \%)$ responden tidak karies. Hasil uji statistik didapatkan nilai $p$-value $=0,002$ lebih kecil dari nilai alpha $(p<0,05)$ yang berarti ada hubungan yang bermakna antara kebiasaan menggosok gigi dengan kejadian karies gigi pada murid di TK Kuntum Mekar dan TK Setia Bandar Lampung Tahun 2019. Dari hasil analisis juga diperoleh nilai $\mathrm{OR}=7.333$, artinya responden yang memiliki kebiasaan menggosok gigi kurang baik beresiko mengalami karies gigi 7,3 kali lebih besar dibandingkan dengan responden yang memiliki kebiasaan menggosok gigi baik.

\section{PEMBAHASAN}

\section{Konsumsi Makanan Kariogenik}

Berdasarkan hasil penelitian didapatkan bahwa murid yang mengkonsumsi makanan kariogenik sering $72(86,0 \%)$ murid dengan tingkat konsumsi makanan kariogenik sering dan $8(14,0 \%)$ jarang.

\section{Kejadian Karies Gigi}

Didapatkan sebagian besar kejadian karies gigi sebanyak $63(84,8 \%)$. Menggosok gigi setelah makan dan sebelum tidur adalah kegiatan rutin sehari-hari. Tujuannya untuk memperoleh kesehatan gigi dan mulut yang sehat. Frekuensi menggosok gigi maksimal $3 x$ sehari (setelah makan pagi, makan siang, dan sebelum tidur malam), atau minimal $2 x$ sehari.Menggosok gigi wajib sebelum tidur karena saat tidur air ludah berkurang sehingga asam yang dihasilkan oleh plak menjadi lebih pekat dan dapat meningkatkan kerusakan pada gigi.Menggosok gigi setelah sarapan pagi sehingga kondisi mulut tetap bersih sampai makan siang (Sariningsih, 2012; Maryam, 2008). Hal ini sesuai dengan hasil penelitian, tentang hubungan frekuensi konsumsi makanan kardiogenik dan menggosok gigi dengan kejadian karies gigi pada anak pra sekolah usia 4-6 tahun di TK Anak Cerdas PP Paudni Kabupaten Semarang didapatkan responden berada dalam kategori kebiasaan menggosok gigi tidak baik sebesar $52,6 \%$. (Rani, \& Waluyo, 2016).

Dari hasil analisa peneliti diperoleh masalah tentang buruknya kebiasaan menggosok gigi dengan presentasi sebesar 60 (75,0\%). Karena anak-anak umumnya kurang pengetahuan tentang cara menyikat gigi yang benar pada anak-anak.

Riska Wandini' Dosen Program Studi llmu Keperawatan Universitas Malahayati. Email: onienay@yahoo.co.id Yuniati ${ }^{2^{*}}$ Perawat di RS Pertamina Bintang Amin Bandar Lampung. *Email: yuniaticantik18@gmail.com 


\section{Hubungan Konsumsi Makanan Kariogenik Dengan Kejadian Karies Gigi}

Berdasarkan hasil analisis bivariat, bahwa dari bahwa dari 72 (100,0\%) responden dengan konsumsi makanan kariogenik yang sering terdapat $60(84,2 \%)$ responden mengalami karies gigi dan $12(15,8 \%)$ responden tidak mengalami karies gigi. Sedangkan dari $8(100,0 \%)$ responden dengan konsumsi makanan kariogenik jarang terdapat $3(58,3 \%)$ responden yang mengalami karies dan $5(41,7 \%)$ responden tidak karies. Hasil uji statistik didapatkan nilai $p$-value $=0,022$ lebih kecil dari nilai alpha $(p<0,05)$ yang berarti ada hubungan yang bermakna antara frekuensi konsumsi makanan kariogenik dengan kejadian karies gigi pada anak. Dari hasil analisis juga diperoleh nilai $\mathrm{OR}=5.357$, artinya responden dengan konsumsi makanan kariogenik sering beresiko mengalami karies gigi 5,3 kali lebih besar dibandingkan dengan responden yang mengkonsumsi makanan kariogenik jarang.

$\mathrm{Hal}$ ini sesuai dengan teori, makanan kardiogenik adalah makanan yang dapat menyebabkan terjadinya karies gigi. Sifat makanan kariogenik adalah banyak mengandung karbohidrat, lengket, dan mudah hancur di dalam mulut seperti permen, coklat, biscuit, roti manis, kue-kue, ice cream dan susu. Pengulangan konsumsi karbohidrat yang terlalu sering menyebabkan produksi asam oleh bakteri menjadi lebih sering sehingga rongga mulut menjadi lebih asam dan semakin banyak email yang terlarut yang menyebabkan karies gigi (Rani, \& Waluyo, 2016).

Berdasarkan penelitian yang ada peneliti berpendapat bahwa murid yang lebih sering mengkonsumsi makanan kariogenik lebih banyak mengalami karies gigi dibandingkan murid yang jarang mengkonsumsi makanan kariogenik. Karena sebagian besar frekuensi mengkonsumsi makanan kariogenik tidak hanya disekolah saja tetapi juga di rumah, hal ini menunjukkan pengulangan konsumsi makanan kariogenik yang terlalu sering akan menyebabkan makanan tersebut akan lama menempel pada gigi sehingga dari waktu ke waktu akan terjadinya karies gigi.Pengurangan karies bersifat bimodal dan pada anak usia muda $75-80 \%$ karies gigi terjadi setidaknya pada $20-25 \%$ populasi. Anak usia muda yang dibiarkan tidur sambil mengisap botol merupakan penyebab utamanya (Anggraeni, \& Aryanto, 2019).

\section{Hubungan Kebiasaan Menggosok Gigi dengan Kejadian Karies Gigi}

Dari $20(100,0 \%)$ responden yang memiliki kebiasaan menggosok gigi yang baik terdapat 17 $(60,0 \%)$, responden mengalami karies gigi dan 3 $(40,0 \%)$ responden tidak mengalami karies gigi. Sedangkan dari $60(100,0 \%)$ responden yang memiliki kebiasaan menggosok gigi kurang baik terdapat $46(91,7 \%)$, responden yang mengalami karies dan $14(8,3 \%)$ responden tidak karies. Hasil uji statistik didapatkan nilai $p$-value $=0,002$ lebih kecil dari nilai alpha $(p<0,05)$ yang berarti ada hubungan yang bermakna antara kebiasaan menggosok gigi dengan kejadian karies gigi. Dari hasil analisis juga diperoleh nilai $\mathrm{OR}=7.333$, artinya yang memiliki kebiasaan menggosok gigi kurang baik beresiko mengalami karies gigi 7,3 kali lebih besar dibanding dengan responden yang memiliki kebiasaan menggosok gigi baik. Menggosok gigi gunanya untuk membersihkan gigi dan gusi terhadap sisa makanan dan plak yang melekat pada gigi yang dapat mengakibatkan karies gigi, serta dapat menghindari tebentuknya lubang-lubang gigi dan penyakit gigi dan juga gusi (Endang, 2012).

Hasil penelitian hubungan antara frekuensi konsumsi makanan kariogenik dan menggosok gigi dengan kejadian karies gigi dengan uji statistik didapatkan hasil $p$-value 0,002 menunjukkan adanya hubungan kebiasaan menggosok gigi dengan kejadian karies gigi (Rani, \& Waluyo, 2016).

Pada anak prasekolah biasanya menggosok gigi tidak dilakukan dengan efisien (Ratih, 2008). Pengetahuan anak TK tentang cara menggosok gigi yang baik harus ditingkatkan agar kejadian karies gigi yang sering dialami anak TK berkurang dan agar siswa menerapkan tidak hanya dalam tahap tahu saja tetapi harus bias menerapkan dalam kehidupannya. Sehingga perlu dukungan dari pihak puskesmas dan pihak pendidikan. Namun hal ini juga berkaitan dengan karakteristik anak usia pra sekolah.Pada penelitian ini mengapa ada hubungan kebiasaan menggosok gigi terhadap kejadian karies, dikarenakan adanya faktor cara menggosok gigi yang kurang baik. Menggosok gigi adalah cara yang umum dianjurkan untuk membersihkan deposit lunak pada permukaan gigi dan gusi, dan bila cara menggosok gigi kurang baik maka sisa-sisa makanan akan mengendap dan menempel digigi sehingga terjadinya penimbunan plak yang dapat menyebabkan terjadinya karies gigi.Perjalanan karies gigi adalah

Riska Wandini' Dosen Program Studi llmu Keperawatan Universitas Malahayati. Email: onienay@yahoo.co.id Yuniati ${ }^{2^{*}}$ Perawat di RS Pertamina Bintang Amin Bandar Lampung. *Email: yuniaticantik18@gmail.com 
Konsumsi makanan kariogenik dan kebiasaan menggosok gigi dengan kejadian karies gigi pada anak

email gigi dirusak oleh asam laktat yang terbentuk, sedangkan garam $\mathrm{Ca}$ dari email dilarutkan sehinggga bahan interprismatik melepaskan prisma-prismanya (Deynilisa, 2015).

Gigi umunya berongga ditengah, disebut rongga pulpa yang berisi pulpa gigi. Bagiannya adalah : Rongga pulpa, tanduk pulpa, saluran pulpa, foramen apical, saluran tambahan dan orifis (Itjingningsih, 2013).

Berdasarkan penelitian yang ada peneliti berpendapat bahwa murid yang kebiasaan menggosok gigi kategori kurang baik lebih banyak mengalami karies gigi dibandingkan dengan murid yang kebiasaan menggosok gigi yang baik dan benar atau menggosok gigi setelah sarapan pagi dan sebelum tidur malam.

\section{SIMPULAN}

Berdasarkan penelitian yang telah dilakukan maka dapat diambil kesimpulan bahwa hasil yang diperoleh adalah sebagai berikut :

Konsumsi makanan kariogenik sering sebanyak 72 responden $(86 \%)$, sedangkan frekuensi makanan kariogenik jarang sebanyak 8 orang $(14 \%)$.Kebiasaan menggosok gigi kurang baik sebanyak 60 responden $(75 \%)$, sedangkan kebiasaan menggosok gigi baik sebanyak 20 orang $(25 \%)$. Karies gigi pada anak-anak dengan karies sebanyak 63 responden $(83,8 \%)$, sedangkan yang frekuensi tidak karies sebanyak 17 orang (16,2\%). Ada hubungan antara konsumsi makanan kariogenik dengan kejadian karies gigi pada anak dengan nilai $p$-value $=0,022$ ( $p$-value $<0,05)$, serta diperoleh nilai $\mathrm{OR}: 5.357$. Ada hubungan antara menggosok gigi dengan kejadian karies gigi pada anak dengan nilai $p$-value $=0,002$ ( $p$-value $<0,05)$, serta diperoleh nilai OR : 7.333 .

\section{SARAN}

Peran guru dan orangtua supaya selalu mengingatkan anak-anak mengurangi konsumsi makanan kariogenik agar tidak memicu timbulnya kerusakan pada gigi dan lebih mengetahui cara menggosok gigi dengan benar. Memberikan pengetahuan kesehatan gigi pada anak didik dengan cara penyuluhan kesehatan, terutama yang berhubungan dengan makanan kariogenik dan kebiasaan menggosok gigi, agar anak didik mampu memahami cara mencegah terjadinya penyakit gigi dan mulut terutama pada gigi karies.Dan bagi peneliti selanjutnya dapat melakukan studi lanjutan mengenai faktor-faktor yang mempengaruhi kejadian karies gigi pada anak, seperti derajat keasaman saliva yang dapat menyebabkan terjadinya karies gigi.

\section{DAFTAR PUSTAKA}

Anggraeni, W., \& Aryanto, M. (2019). Perbedaan pengaruh apel Anna dan Granny Smith sebagai bahan pemutih gigi alami Differences between Anna and Granny Smith apples as natural tooth whitening ingredients. Jurnal Kedokteran Gigi Universitas Padjadjaran, 31(1), 22-27.

Badan Penelitian Indonesia. (2013). Kementerian Kesehatan Rl. Riset kesehatan dasar (Riskesdas).

Deynilisa, S. (2015). IImu Konservasi Gigi. Jakarta: Penerbit Buku Kedokteran EGC.

Endang, S. (2012). Merawat Gigi Anak Sejak Usia Dini.

Erwana, A. F. (2013). Seputar kesehatan gigi dan mulut. Yogyakarta: Rapha Publishing.

Hidayat, R, \& Tandiari, A. (2016). Kesehatan Gigi dan Mulut-Apa yang Sebaiknya Anda Tahu?. Penerbit Andi.

Hongini, Y. S., \& Aditiawarman, M. (2012). Kesehatan gigi dan mulut. Bandung: Pustaka Reka Cipta.

Mansjoer, A., Suprohaita, W. W., \& Setiowulan, W. (2008). Kapita Selekta Kedokteran, Jilid 2 Edisi III. Media Aesculapius FKUI. Jakarta. Hal, 99.

Maryam, S. (2008). Menengenal usia lanjut dan perawatannya. Penerbit Salemba.

Mumpuni, Y., \& Pratiwi, E. (2013). Masalah dan Solusi Penyakit Gigi dan Mulut. Andi Offset. Yogyakarta.

Notoatmodjo, S. (2012). Metodologi penelitian kesehatan (Cetakan VI). Jakarta: Penerbit PT. Rineka Cipta.

Riska Wandini' Dosen Program Studi llmu Keperawatan Universitas Malahayati. Email: onienay@yahoo.co.id Yuniati ${ }^{2^{*}}$ Perawat di RS Pertamina Bintang Amin Bandar Lampung. *Email: yuniaticantik18@gmail.com 
Konsumsi makanan kariogenik dan kebiasaan menggosok gigi dengan kejadian karies gigi pada anak

Pintauli, S., Bachtiar, A., \& Rahardjo, A. (2019). Pengembangan Model Edukasi Kesehatan Gigi Mandiri dalam Pengendalian Faktor Risiko Karies pada Kalangan Remaja Melalui Pemanfaatan Gadget.

Putri, A. B., \& Sari, L. (2012). Prilaku Menjaga Kebersihan Gigi dan Mulut terhadap Kejadian Karies Gigi pada Siswa Kelas IV SDN 1 Gunung Sulah Kecamatan Sukarane Bandar Lampung. Jurnal Dunia Kesmas, 1(3).

Ramadhan, A. G. (2010). Serba serbi kesehatan gigi dan mulut. Jakarta: Bukune, 186.

Rani, D. M., \& Waluyo, S. T. K. N.( 2016). Hubungan frekuensi konsumsi makanan kariogenik dan menggosok gigi dengan kejadian karies gigi pada anak pra sekolah usia 4-6 tahun di tk anak cerdas pp paudni kabupaten semarang.
Ratih,DN (2008). Perpindahan cuspal dalam asosiasi dengan penyusutan stres polimerisasi. Majalah Ilmu Kedokteran Gigi, 10 (2008).

Sariningsih, E. (2012). Merawat Gigi Anak Sejak Usia Dini. Jakarta: Elex Media Komputindo.

Susanto, G. W., \& Grace, W. (2011). Terapi gusi untuk kesehatan dan kecantikan. Semarang: Airlangga.

Talibo, R. S., Mulyadi, N., \& Bataha, Y. (2016). Hubungan Frekuensi Konsumsi Makanan Kariogenik Dan Kebiasaan Menggosok Gigi Dengan Kejadian Karies Gigi Pada Siswa Kelas III Sdn 1 \& 2 Sonuo. Jurnal keperawatan, 4(1).

Tarigan, R. (2013). Karies gigi. Jakarta: EGC.

Wangidjaja, I. (2014). Anatomi gigi. Jakarta: Buku kedokteran EGC, 293-8.

Riska Wandini' Dosen Program Studi llmu Keperawatan Universitas Malahayati. Email: onienay@yahoo.co.id Yuniati ${ }^{2^{*}}$ Perawat di RS Pertamina Bintang Amin Bandar Lampung. *Email: yuniaticantik18@gmail.com 